\title{
ACADEMIC PERFORMANCE, CLASS ATTENDANCE AND SEATING LOCATION OF UNIVERSITY STUDENTS IN PRACTICAL LECTURE
}

\author{
José Manuel Navarro Jover (iD, José Antonio Martínez Ramírez (D) \\ Universitat Politècnica de València (Spain) \\ jnavar@dig.upv.es,tmartin@upvnet.upv.es
}

Received December 2017

Accepted April 2018

\section{Abstract}

The question of where students sit in a classroom has been widely studied under different approaches since the beginning of the 20th century. In this study, the data related to the seating location of the students in the computer-aided design practice lecture at the university were recorded and arranged, to analyse their seating preferences, their consistency throughout the course and their relationship with several factors related to academic performance, class attendance, and punctuality. In general, it was observed that students are reluctant to seat on the first row, and that the most punctual students chose to occupy the places in the first rows, closer to the lecturer $(\mathrm{r}=0.35, \mathrm{p}=0.015)$, although this had no impact on academic performance. While the following was indeed correlated with the attendance rate: those students who attended the most class achieved a better academic performance which was reflected in the final mark $(\mathrm{r}=0.38, \mathrm{p}=0.007)$. No difference was observed in any aspect between male and female students.

Keywords - Student, Seating, Location, Classroom, Performance.

\section{Introduction}

Traditionally it has been said that, in general, students who chose to sit at the end of the class are the least gifted, as opposed to those who occupy the first row. Most lectures would agree that it is difficult to connect with all students in an average class (Shernoff, Sannella, Schorr, Sanchez-Wall, Ruzek, Sinha et al., 2017), especially if it is a master class or presentation, but also in the case of more participatory lectures. Those in the last rows may be uninterested or absent-minded, while those in the first can devote their attention to the lecturer more easily. If the class is very large and of an expository nature, all this seems even more obvious, as well as more complicated for the lecturer to reach all the students, or to know them by their names and to be able to interact with them individually (Armstrong \& Chang, 2007).

The literature proves the influence of the seating place occupied by students on their attitude in the classroom, attention, participation, positive attitude and commitment. All these features are greater in those students located in front compared to those located further back (Montello, 1988, Minchen, 2007, Shernoff et al. 2017; Perkins \& Wieman, 2005; Benedict \& Hoag, 2004; Vander Schee, 2011). Nevertheless, the question is not so clear as to whether all these factors lead to a higher academic performance by the students. Some studies have found a negative relationship between the distance from the blackboard and academic performance (Zomoridian, Parva, Ahrari, Tavana, Hemyari, Pakshir et al., 2012). While this has not been found in many others or very weak results were found (Meeks, Knotts, James, Williams, Vassar \& Wren, 2013; Kalinowski \& Taper, 2007; Millard \& Stimpson, 1980). Herrero, Llorens, Oliver, Silva and Tamarit (2012) concluded that this influence did take place in theory lecturers (where the role of the lecturer is more relevant) but not in practical lectures. 
Other works have focused on analysing the preferences of the students when choosing where they seat in class (Cinar, 2010) or the relation between the seat chosen with other factors such as gender (female students sit further up front than male students), the origin of the students (those students who lived in cities sit further up front than those who lived in smaller towns), or the mother's studies, as well as the consistency in the seating location occupied. Burda and Brooks (1996) observed that the students who chose to sit in the first rows turned out to be those who had higher levels of motivation towards success, and concluded that it was these intrinsic personality traits that determined the place chosen by students in the classroom. In the same vein, Hemyari, Zomorodian, Ahrari, Tavana, Parva, Pakshir et al. (2013) observed that the places chosen by the students were related to certain personal traits (sympathy, degree of interest). Particularly in this regard we have observed that students are reluctant to occupy the first row (or first rows in larger lecture halls), especially in the case of first-year students.

Minchen (2007) suggests that the awareness of all these relationships of the seating location with the attitude, interaction with the lecturer, and possibly with the performance, could be taken into account and be used by the lecturer to try to help or channel students who struggle the most to pass the courses.

This study analyses the seating location chosen by the students in an IT room during computer-aided design practice lectures, their consistency throughout the course and their relationship with several factors related to academic performance, class attendance, and punctuality. The aim is not to establish guidelines or a detailed plan of placement and/or rotation of the students, but to check whether there are any differences in the performance obtained in this type of class and to find out whether there are any preferences or patterns of behaviour in the election of the place they occupy.

The final aim is to record and organise the data related to the location of students in the classroom, to analyse their relationship with academic performance and other academic variables (such as attendance, punctuality). The starting hypotheses are: a) Those students who seat closer to the lecturer and are better positioned with respect to the projector (closer and not an angle) obtain better qualifications. $b$ ) Those students with a higher class attend rate achieve better marks. c) Students do not always sit in the same place. Those who normally arrive late to class tend to choose seating positions farther away from the lecturer. d) Students (especially in the first year) do not like to sit in the first or first front rows. e) Female students tend to sit in the front rows more often and therefore get better grades than male students.

\section{Methodology}

This study has been carried out in two practice groups of the course Graphic Representation in Engineering, belonging to the degree in Rural and Agrifood Engineering of the School of Agricultural Engineering and the Environment of the Universitat Politècnica de València, in academic year 2016/17. There was a total of 16 practice sessions (one per week, with duration of 120 minutes each). Both groups (B1 and B2) share the same classroom and have the same lecturer, and the weekly practical lecture takes place on different days and at the same time:

- B1: Wednesday 8:00 h; 24 students

- $\quad$ B2: Tuesday 8:00 h; 25 students

Figure 1 shows the floor plan of the IT room. It is equipped with 32 computer stations distributed across four rows and eight columns. Students occupy positions freely upon arrival to class in each session, and the computer number occupied by each one is recorded in the system (Table 1). The location of each computer station has been recorded in relation to the position of the lecturer's desk and the location of the projector (Table 2). During the practice class, the lecturer alternates explanations and demonstrations from his desk using the computer connected to the projector, including going around the classroom to provide feedback and answer questions from the students. 


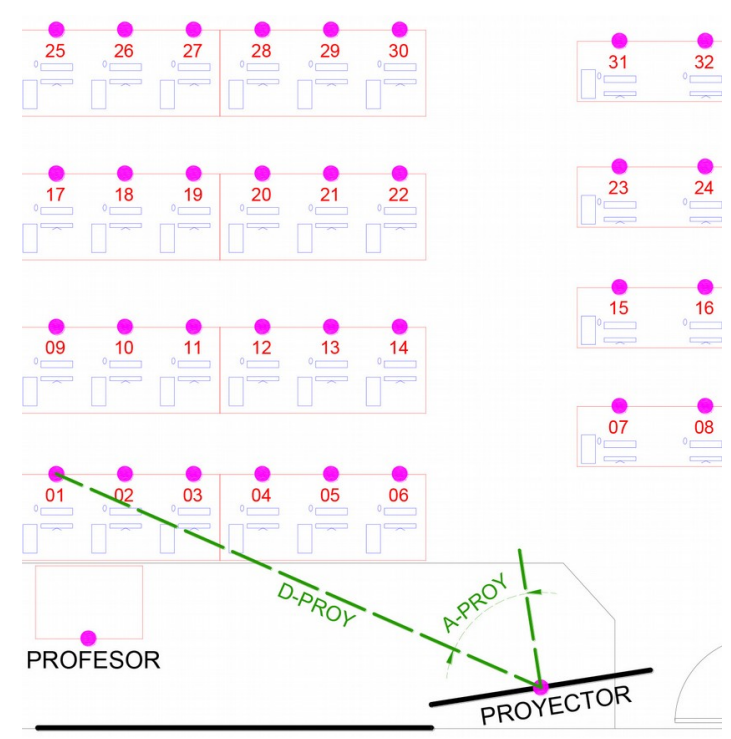

Figure 1. Distribution of positions (computers) in the IT room

\begin{tabular}{|l|l|c|c|c|}
\hline \multicolumn{1}{|c|}{ USER } & COMPUTER & TIME_IN & TIME_OUT & TIME (MIN.) \\
\hline ALAGMO & AGR10618 & Wedn $(10 / 2 / 16)-08: 33$ & Wedn $(10 / 2 / 16)-10: 36$ & 123.05000 \\
\hline ALAGMO & AGR10626 & Wedn $(17 / 02 / 2016)-08: 30$ & Wedn $(17 / 02 / 2016)-08: 30$ & 0.01667 \\
\hline ALAGMO & AGR10625 & Wedn $(24 / 02 / 2016)-08: 35$ & Wedn $(24 / 02 / 2016)-08: 35$ & 0.00000 \\
\hline ALAGMO & AGR10627 & Wedn $(09 / 03 / 2016)-08: 35$ & Wedn $(09 / 03 / 2016)-10: 54$ & 139.85000 \\
\hline ALAGMO & AGR10625 & Wedn $(16 / 03 / 2016)-08: 32$ & Wedn $(16 / 03 / 2016)-10: 40$ & 128.91667 \\
\hline ALAGMO & AGR10625 & Wedn $(23 / 03 / 2016)-08: 34$ & Wedn $(23 / 03 / 2016)-08: 45$ & 11.06667 \\
\hline ALAGMO & AGR10623 & Wedn $(23 / 03 / 2016)-08: 47$ & Wedn $(23 / 03 / 2016)-10: 55$ & 127.83333 \\
\hline ALAGMO & AGR10616 & Wedn $(06 / 04 / 2016)-08: 34$ & Wedn $(06 / 04 / 2016)-10: 46$ & 132.16667 \\
\hline ALAGMO & AGR10619 & Wedn $(13 / 04 / 2016)-08: 31$ & Wedn $(13 / 04 / 2016)-10: 44$ & 133.45000 \\
\hline ALAGMO & AGR10628 & Wedn $(20 / 04 / 2016)-08: 31$ & Wedn $(20 / 04 / 2016)-10: 49$ & 138.06667 \\
\hline ALAGMO & AGR10629 & Wedn $(27 / 04 / 2016)-08: 35$ & Wedn(27/04/2016) - 11:01 & 145.75000 \\
\hline ALAGMO & AGR10619 & Wedn $(04 / 05 / 2016)-08: 34$ & Wedn $(04 / 05 / 2016)-10: 33$ & 118.96667 \\
\hline ALAGMO & AGR10617 & Wedn $(11 / 05 / 2016)-08: 35$ & Wedn $(11 / 05 / 2016)-10: 50$ & 134.76667 \\
\hline ALAGMO & AGR10625 & Wedn $(18 / 05 / 2016)-08: 36$ & Wedn $(18 / 05 / 2016)-10: 09$ & 92.55000 \\
\hline ALBLABLA & AGR10607 & Tuesd $(02 / 02 / 2016)-08: 12$ & Tuesd $(02 / 02 / 2016)-10: 41$ & 148.78333 \\
\hline ALBLABLA & AGR10607 & Tuesd $(09 / 02 / 2016)-08: 08$ & Tuesd $(09 / 02 / 2016)-10: 27$ & 138.68333 \\
\hline ALBLABLA & AGR10607 & Tuesd $(16 / 02 / 2016)-08: 09$ & Tuesd $(16 / 02 / 2016)-08: 09$ & 0.00000 \\
\hline
\end{tabular}

Table 1. SHEET 1. Access log to computers during practice sessions

\begin{tabular}{|l|c|c|c|c|c|}
\hline PC & ROW & COL & DPROY $(\mathbf{c m})$ & APROY $\mathbf{~}^{\mathbf{}}$ ) & DPROF (cm) \\
\hline AGR10601 & 1 & 1 & 616.6 & 57 & 194.6 \\
\hline AGR10602 & 1 & 2 & 544.3 & 54 & 226.9 \\
\hline AGR10603 & 1 & 3 & 474.5 & 50 & 278.4 \\
\hline AGR10604 & 1 & 4 & 408.4 & 44 & 341 \\
\hline AGR10605 & 1 & 5 & 348.3 & 36 & 409.7 \\
\hline AGR10606 & 1 & 6 & 297.6 & 25 & 674.9 \\
\hline AGR10607 & 1 & 7 & 339.6 & 25 & 767.6 \\
\hline AGR10608 & 1 & 8 & 379 & 39 & 363.9 \\
\hline AGR10609 & 2 & 1 & 703 & 45 & $\ldots$ \\
\hline$\ldots$ & $\ldots$ & $\ldots$ & $\ldots$ & $\ldots$ & $\ldots$ \\
\hline
\end{tabular}

Table 2. SHEET 2. Location of each computer in the classroom with respect to the projector and the lecturer 
Table 3 describes all the variables included in the study, which can be grouped into three types:

- Position variables in the classroom

- Class attendance

- Academic performance

Table 4 displays the final table that has been used for the statistical analysis described in section 2.4. It contains, for each student (row) the variables that have been described in Table 3, together with the identifier (name, username) and the categorical variables class group and gender.

\begin{tabular}{|c|c|c|}
\hline \multirow{5}{*}{$\begin{array}{l}\text { Positional } \\
\text { variables (average } \\
\text { during the } \\
\text { course) }\end{array}$} & ROW & Row occupied by the student in class: from 1 to 4 \\
\hline & COL & Column occupied by the student in class: from 1 to 8 \\
\hline & D-PROJ & Distance to the projector $(\mathrm{cm})$ \\
\hline & A-PROJ & $\begin{array}{l}\text { Angle between the perpendicular line from the centre of the projector and the } \\
\text { student-projector line (sexagesimal degrees) }\end{array}$ \\
\hline & D-PROF & Distance to the professor (lecturer) $(\mathrm{cm})$ \\
\hline \multirow{4}{*}{ Attendance } & NSES & Number of sessions (days) attended (between 0 and 16) \\
\hline & TIME & Average time the PC was connected in each session \\
\hline & NPCS & Number of different positions (computers) used in the course \\
\hline & ENTR & $\begin{array}{l}\text { Time of entry to the class (log time when accessing the computer) (minutes } \\
\text { from the start time of the class) }\end{array}$ \\
\hline \multirow{3}{*}{$\begin{array}{l}\text { Academic } \\
\text { performance }\end{array}$} & N-FIN & Final mark $(0-10)$ in the course $(=0.6 *$ N-CTRL $+0.4 *$ N-PRAC $)$ \\
\hline & N-CTRL & $\begin{array}{l}\text { The mark (0-10) of the mid-year exams (two mid-term and end of the year } \\
\text { exams) }\end{array}$ \\
\hline & N-PRAC & Average mark (0-10) of the practical cases carried out in class daily \\
\hline
\end{tabular}

Table 3. Variables considered in the study

\begin{tabular}{|c|c|c|c|c|c|c|c|c|c|c|c|c|c|c|c|}
\hline \multirow[b]{2}{*}{$\sum_{Z}^{\mid}$} & \multirow[b]{2}{*}{ 爯 } & \multirow[b]{2}{*}{\begin{tabular}{l}
5 \\
0 \\
0 \\
\multirow{0}{*}{}
\end{tabular}} & \multirow[b]{2}{*}{ 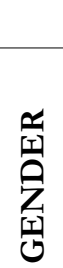 } & \multicolumn{3}{|c|}{ ACADEM PERF. } & \multicolumn{5}{|c|}{ POSITION } & \multicolumn{4}{|c|}{ ATTENDANCE } \\
\hline & & & & $\begin{array}{l}\text { 空 } \\
\text { 安 }\end{array}$ & 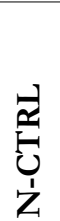 & $\begin{array}{l}u \\
\frac{1}{2} \\
\frac{1}{2}\end{array}$ & 里 & Oे & 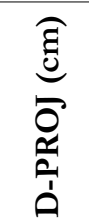 & 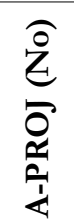 & 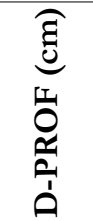 & $\begin{array}{l}\infty \\
\text { II } \\
\text { Z }\end{array}$ & $\begin{array}{l}\infty \\
\dot{Z}\end{array}$ & 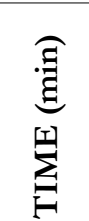 & 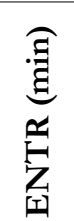 \\
\hline & & 1 & 2 & 6.1 & 3.7 & 5.8 & 3.5 & 3.0 & 810.6 & 24.3 & 685.5 & 14.0 & 10.0 & 101.9 & 34.4 \\
\hline & & 1 & 2 & 5.0 & 1.3 & 6.0 & 1.0 & 4.7 & 384.4 & 39.1 & 354.7 & 13.0 & 4.0 & 109.4 & 30.9 \\
\hline & & 1 & 2 & 9.1 & 9.2 & 8.9 & 2.2 & 4.0 & 578.2 & 28.9 & 473.3 & 12.0 & 8.0 & 111.4 & 32.3 \\
\hline & & 1 & 1 & 5.2 & 3.7 & 6.2 & 2.5 & 3.4 & 647.4 & 26.4 & 477.6 & 11.0 & 9.0 & 99.9 & 34.5 \\
\hline & & 1 & 2 & 5.0 & 2.8 & 5.0 & 3.5 & 3.6 & 777.0 & 19.1 & 673.6 & 14.0 & 9.0 & 112.2 & 31.7 \\
\hline & & 1 & 1 & 3.0 & 1.5 & 2.6 & 3.5 & 4.9 & 742.3 & 14.8 & 732.5 & 12.0 & 9.0 & 112.2 & 29.0 \\
\hline & & 1 & 2 & 4.6 & 2.0 & 5.8 & 3.4 & 2.9 & 797.0 & 23.5 & 657.2 & 10.0 & 8.0 & 114.5 & 32.6 \\
\hline & & 1 & 2 & 5.2 & 5.1 & 5.5 & 3.6 & 2.9 & 815.0 & 21.6 & 655.5 & 13.0 & 6.0 & 101.3 & 30.4 \\
\hline$\ldots$ & $\ldots$ & $\ldots$ & $\ldots$ & $\ldots$ & $\ldots$ & $\ldots$ & $\ldots$ & $\ldots$ & $\ldots$ & $\ldots$ & $\ldots$ & $\ldots$ & $\ldots$ & $\ldots$ & $\ldots$ \\
\hline
\end{tabular}

Table 4. Total set of variables and data related to each student

Three spreadsheets have been developed to achieve all these data for each student:

- SHEET 1. ACCESS LOG TO THE COMPUTERS (Table 1). It is an automatic log developed by the computer service of the School of Agricultural Engineering and the Environment, which contains all the logging records of any student (USER) to any computer (PC) in the classroom: date, logging time, logout time. For the purpose of this study, only the login records to computers 
during the days and hours in which the practice sessions of the course under study took place have been included; which resulted in a total of 615 logins.

- SHEET 2: SITUATION OF COMPUTERS IN THE CLASSROOM (see Table 2). It contains, for each computer (PC column), its positional data in the classroom: ROW (row, from 1 to 4 , COL (column, from 1 to 8), D-PROF (distance to the lecturer, $\mathrm{cm}$ ), D-PROJ (distance to the projector, $\mathrm{cm}$ ), A-PROJ (angle at which the student looks at the projector with respect to the perpendicular line thereof, in sexagesimal degrees). All these data have been obtained by measuring the Figure 1 plane with the help of AutoCAD 2018 (Figure 1 describes the example for computer 01).

- SHEET 3: LIST OF STUDENTS It contains the field USER (which will be used to link it to SHEET 1) and also the academic performance results.

\subsection{Obtention of Positional Data}

Based on SHEET 3 (list of students), the other two sheets are filtered and linked using Excel search formulas and their location data are calculated for each student (USER) (middle row, middle column, average distance to the lecturer, average distance to the projector, average angle with the projector) in the classroom in each practice class session, using the common USER and PC fields.

Then, using dynamic tables, the average location data is calculated for each student on the Excel sheet itself (middle row, middle column, average distances...) for the full academic year (total sessions attended).

\subsection{Attendance Variables}

Like in the previous section, based on SHEET 3 and linking SHEET 1, the attendance data of each student is obtained: it is recorded which computer was used by each student each day and for how long it was used.

Afterwards, all the assistance data are compiled for each user: number of sessions attended (NSES), punctuality (ENTR), number of different positions occupied (NPCS).

Finally, the average location data in the classroom are added for each user (from the computer used).

\subsection{Academic Performance}

The data of the students' academic results, gathered in the follow-up records of the course by the lecturer, have been used:

- N-CLTR: average mark obtained in the two mid-course exams carried out during the academic year

- N-PRAC: mark obtained in the exercises carried out in class

- N-FIN: final mark of the academic year. It is obtained from the previous two: N-FIN $=0.6^{*}$ N-CTRL + 0.4* N-PRAC

\subsection{Statistical Analysis}

A bivariate analysis has been carried out, with all available variables (performance, position and attendance), to obtain all the correlation coefficients (Pearson's r) and explore if there are correlations among them.

Likewise, a contrast of means has been performed for all variables to explore possible differences between students, as well as between both class groups. The effect size (Cohen's d) was also calculated to shed some light on the relevance of these possible differences.

The statistical package GNU PSPP 0.10 .1 has been used. 


\subsection{Occupation Ratio of Each Position}

Using the data in Table 1 (access log), a thematic map has been drawn to see the occupation ratio of each IT position.

\section{Results and Discussion}

Figure 2 displays the box plot for the NSES variable (class attendance).

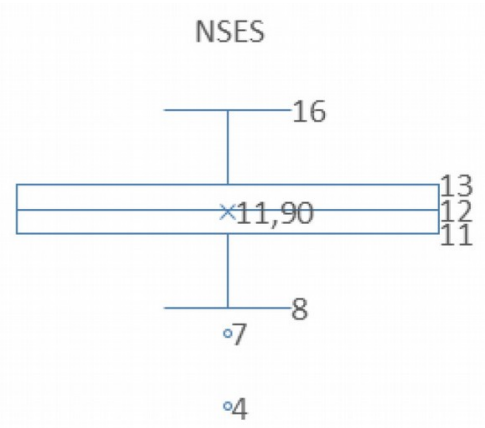

Figure 2. Box plot for the NSES variable

The attendance ratio was high: $75 \%$ of the students attended at least $70 \%$ of the 16 total sessions $(\mathrm{Q} 1=11$ sessions). The average was 12 assisted sessions, during which each student used an average of 6 different computers (average NPCS was 6).

The correlations between the most relevant variables are described below.

The final mark (N-FIN) and the mark for the practical cases carried out in class (N-PRAC) are positively related to the number of sessions attended (NSES) $(r=0.38, p=0.007$, and $r=0.43, p=0.002$ respectively). The students with the highest attendance ratio were the ones with the best marks. But they were not necessarily the ones who sit closest to the blackboard. This is in accordance with the results obtained by Pérez and Graell (2004) in medical students.

The distance of the students to the lecturer (D-PROF) and the occupied row (ROW) are positively related to the arrival time $(E N T R)(r=0.35, p=0.015$, and $r=0.35 \mathrm{mp}=0.015)$. Students who arrive later tend to sit farther away from the lecturer and the blackboard.

The number of different positions (or computers) used (NPCS) during the academic year is positively related to distance to the lecturer $(\mathrm{r}=0.41, \mathrm{p}=0.003)$ and to the projector $(\mathrm{r}=0.56, \mathrm{p}=0.000)$ and occupied row $(\mathrm{r}=0.62, \mathrm{p}=0.000)$ and also to the arrival time ENTR $(\mathrm{r}=0.62, \mathrm{p}=0.000)$. Therefore, students who arrive later to the class use a higher number of different computers during the academic year, and also seat farther away from the lecturer and the projector. Or, in other words, the first to arrive usually sit closer, in the first rows. While they are not the ones who achieve the best mark at the end of the academic year. These results differ from those of Zomorodian et al. (2012), who observed that most students $(82.2 \%)$ chose specific areas while the rest changed their seating location frequently.

Figure 3 shows the height of the number of times each computer was used, by the two groups as a whole. And the most used computers have been highlighted in red (those that are above the median). It is observed that students are reluctant to use the first row, the closest to the lecturer and the blackboard, and also prefer not to use the isolated sections located on the other side of the aisle. 


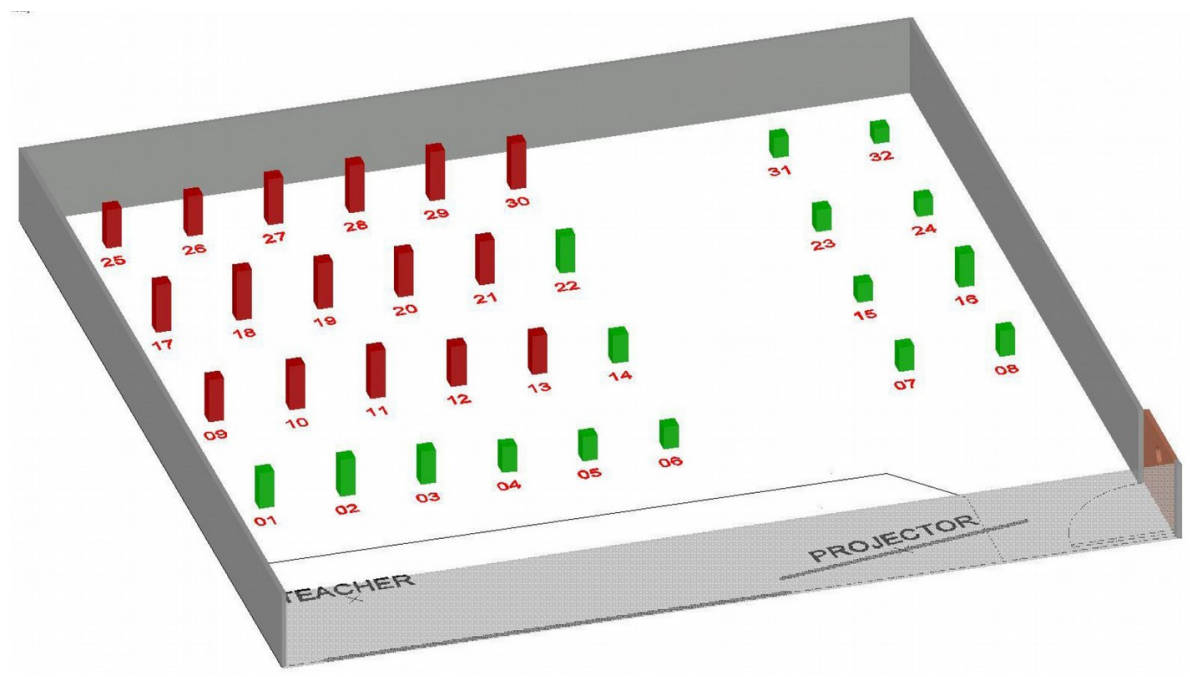

Figure 3. Occupation ratio of each computer. The height is proportional to the number of times used

The N-PRAC (mark for class exercises) and the N-CTRL (mid-year mark) are very related $(\mathrm{r}=0.68$, $\mathrm{p}=0.000$ ). The students who obtain a good mark in the practical cases (exercises carried out in class during the academic year) also do so in the mid-year exams (N-CTRL) (two during the academic year), and in the final mark (N-FIN).

When comparing means between female and male students, no statistically significant difference was observed for any of the variables analysed in the study. Nevertheless, a significant difference was observed when comparing by groups $(p=0.000)$ and quite significant (effect size $d=1.8$ ) regarding arrival time (punctuality) (ENTR): the students of group B1 (Wednesday) arrived, on average, 6:06 minutes later to class than those of group B2 (Tuesday). On the other hand, although the final scores were not significantly different in both groups $(p=0.089, d=0.40)$, group B1 obtained an average final mark, somewhat higher. On the other hand, the level of satisfaction of the students with the work of the lecturer, through the surveys, was higher also in group B1 (1.12 points more in a scale of 10$)$.

\section{Conclusions}

Students who arrive later sit farther away from the lecturer and the blackboard. But the first initial hypothesis is not fulfilled. The performance obtained by the students is not related to the average seating place occupied by such students in the classroom. This agrees with Meeks et al. (2013) and Kalinowski \& Taper (2007). Nevertheless, the shape of the classroom may contribute to this, since it only has 4 rows, the acoustics is quite good, the lecturer is on a platform, all of which may contribute to no important differences in student's attention being found. In addition, being a practical class, and in accordance with the conclusions of Herrero et al. (2012), the degree of supervision and concentration towards the lecturer is lower than in a theory class, and the degree of distraction depends only on the students themselves, rather than on their seating location with respect to the lecturer.

However, the second hypothesis is fulfilled: academic performance is related to attendance, as expected. And this greater attendance is reflected in all the components of the performance: a greater attendance is reflected in better marks obtained in the exercises carried out in class, and also in the exams. This is logical when taking into account that this course, technical drawing, requires the development of a significant spatial vision ability, thus this requires a mental functional gymnastics effort, which can only be developed progressively, week by week, class attendance being very important as this skill is very difficult to acquire based on just revising in a few days or hours.

Students do not always sit in the same place in the classroom. Each student used, on average, six different computers (or six posit) during all the sessions. It may seem a high value, considering that each student attended an average of twelve sessions and that there were 32 positions for 25 students. But as the 
correlations between variables showed, those students who arrive first tend to choose the positions closest to the lecturer and the blackboard. The fact that they seat further up front or at the back is only significantly related to their time of arrival. The later they arrive; the further back they sit. And it is also common that the later they arrive, the more different computers they use, since it is more likely that the one they usually use or have used other times, is busy.

Regardless of the above, it corroborates the idea that students tend to be reluctant to occupy the first row of seats. One possible idea to explore in future studies would be whether overall academic results would be different if students are forced to move forward, which is not unreasonable to consider on the back of the results of Cinar (2010) (those students who prefer to sit towards the front pay more attention in class, are more willing to participate and show more interest and motivation). Also for future work in this line would be interesting to gather information about the opinions and preferences of students about the seating place they occupy in class as well as about their experience and perceptions in the class (motivation, commitment, attention, interaction with the lecturer), drawing on the work by Shernoff et al. (2017).

The differences between groups B1 and B2 regarding the time of entry and final mark, may be due to the fact that the theory class (common for both groups) was scheduled on Tuesday 13:00 h. That is, B2 group students carried out their practice work (Tuesday 8:00 h) before receiving the weekly theory class, and those of group B1 performed them later (Wednesday 8:00 h), just the next day. Although in each weekly theory class the contents related to that current week are never explained, but those of the following week, while it is clear that at the time of each practice class the students of group B1 have the slight advantage of having received one more theory class the day before than their classmates from group B2. In addition, the levels of satisfaction of group B1 students (measured through the results obtained by the lecturer in the lecturer surveys), were better.

The positive relationship between academic performance and class attendance (assuming that the second is the cause of the first) leads us believe, in line with Pérez and Graell (2004), on the importance of motivating students by incorporating increasingly active and participatory methodologies. We are aware that the dissemination and knowledge on the part of students of this positive association between performance and attendance may favour attendance, and therefore contribute to improving performance too.

\section{Declaration of Conflicting Interests}

The authors declared no potential conflicts of interest with respect to the research, authorship, and/or publication of this article.

\section{Funding}

The authors received no financial support for the research, authorship, and/or publication of this article.

\section{References}

Armstrong, N., \& Chang, S.-M. (2007). Location, location, location: Does seat location affect performance in large classes? Journal of College Science Teaching, 37(2), 54-58.

Benedict, M.E., \& Hoag, J. (2004). Seating location in large lectures: Are seating preferences or location related to course performance? Journal of Economic Education, 35(3), 215-231.

https://doi.org/10.3200/JECE.35.3.215-231

Burda, J., \& Brooks, C. (1996). College classroom seating position and changes in achievement motivation over a semester. Psychological Reports, 78, 331-336. https://doi.org/10.2466/pr0.1996.78.1.331

Cinar, I. (2010). Classroom geography: who sit where in the traditional classrooms? Journal of International Research, 3(10), 200-212. 
Hemyari, C., Zomorodian, K., Ahrari, I., Tavana, S., Parva, M., Pakshir, K., et al. (2013). The mutual impact of personality traits on seating preference and educational achievement. European Journal of Psychology of Education, 28(3), 863-877. https://doi.org/10.1007/s10212-012-0144-3

Herrero, C., Llorens, M., Oliver, J., Silva, J., \& Tamarit, S. (2012). Análisis de la relación nota-posición en el aula de los alumnos en escuelas de ingeniería. Actas XVIII JENUI 2012 (377-380). Ciudad Real.

Kalinowski, S., \& Taper, M.L. (2007). The effect of seat location on exam grades and student perceptions in an introductory biology class. Journal of College Science Teaching, 36 (4), 54-57.

Meeks, M.D., Knotts, T.L., James, K.D., Williams, F., Vassar, J.A. \& Wren, A.O. (2013). The impact of seating location and seating type on student performance. Education Sciences, 3(4), 375-386.

https://doi.org/10.3390/educsci3040375

Millard, R.J., \& Stimpson, D.V. (1980). Enjoyment and productivity as a function of classroom seating location. Perceptual and Motor Skills, 50(2), 439-444. https://doi.org/10.2466/pms.1980.50.2.439

Minchen, B.J. (2007). The effects of classroom seating on students' performance in a high school science setting. Education and Human Development Master's Theses. Paper 414. Available at: https://digitalcommons.brockport.edu/ehd theses/414

Montello, D.R. (1988). Classroom seating location and its effect on course achievement, participation, and attitudes. Journal of Environmental Psychology, 8, 149-157. https://doi.org/10.1016/S0272-4944(88)80005-7

Perkins, K.K., \& Wieman, C.E. (2005). The surprising impact of seat location on student performance. The Physics Teacher, 43(1), 30-33. https://doi.org/10.1119/1.1845987

Pérez, J., \& Graell, S. (2004). Asistencia a clase y rendimiento académico en estudiantes de medicina. La experiencia de la Universidad Autónoma de Barcelona. Educación médica, 7(2), 85-89. Available at: http://scielo.isciii.es/pdf/edu/v7n2/original4.pdf

Shernoff, D.J., Sannella, A.J., Schorr, R.Y., Sanchez-Wall, L., Ruzek, E.A., Sinha, S. et al. (2017). Separate worlds: The influence of seating location on student engagement, classroom experience, and performance in the large University lecture hall. Journal of Environmental Psychology, 49, 55-64. https://doi.org/10.1016/j.jenvp.2016.12.002

Vander Schee, B.A. (2011). Marketing classroom spaces: Is it really better at the front? Marketing Education Review, 21(3), 201-210. https:// doi.org/10.2753/MER1052-8008210301

Zomorodian, K., Parva, M., Ahrari, I., Tavana, S., Hemyari, C., Pakshir, K., et al. (2012). The effect of seating preferences of the medical students on educational achievement. Medical Education Online, 17. https://doi.org/10.3402/meo.v17i0.10448

Published by OmniaScience (www.omniascience.com)

Journal of Technology and Science Education, 2018 (www.jotse.org)

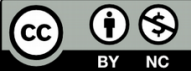

Article's contents are provided on an Attribution-Non Commercial 4.0 Creative commons International License. Readers are allowed to copy, distribute and communicate article's contents, provided the author's and JOTSE journal's names are included. It must not be used for commercial purposes. To see the complete licence contents, please visit https://creativecommons.org/licenses/by-nc/4.0/. 